\title{
Erratum to: Simulation of monsoon intraseasonal variability in NCEP CFSv2 and its role on systematic bias
}

Bidyut B. Goswami - Medha Deshpande · P. Mukhopadhyay •

Subodh K. Saha $\cdot$ Suryachandra A. Rao $\cdot$ Raghu Murtugudde $\cdot$

B. N. Goswami

Published online: 8 January 2015

(C) Springer-Verlag Berlin Heidelberg 2015

Erratum to: Clim Dyn (2014) 43:2725-2745

DOI 10.1007/s00382-014-2089-5

In the original publication, the sixth author name has been incorrectly published as Raghu Murthugudde. The correct name should read as Raghu Murtugudde.

The online version of the original article can be found under doi: 10.1007/s00382-014-2089-5.

B. B. Goswami · M. Deshpande · P. Mukhopadhyay $(\square)$.

S. K. Saha $\cdot$ S. A. Rao $\cdot$ B. N. Goswami

Indian Institute of Tropical Meteorology, Pune 4111008, India

e-mail: mpartha@tropmet.res.in

R. Murtugudde

University of Maryland, College Park, MD 20740, USA 